\title{
WOMEN ON WAVES: O FIM DO PATRIARCALISMO E OS MOVIMENTOS SOCIAIS À LUZ DE UM NOVO FEMINISMO
}

\section{WOMEN ON WAVES: THE END OF PATRIARCHALISM AND SOCIAL MOVEMENTS IN THE LIGHT OF A NEW FEMINISM}

\author{
Romulo Augusto Orlandini \\ Érica Masiero Nering ${ }^{* *}$ \\ Aline Emi Naoe ${ }^{* * *}$
}

\section{RESUMO}

O Women on Waves (WoW) é um movimento social criado para informar mulheres sobre a prevenção de gravidez e aborto. Diante das teorias sobre Novos Movimentos Sociais e dos conceitos de nacionalidade e patriarcalismo buscamos fazer uma análise desse movimento no contexto da contemporaneidade dos movimentos feministas. Como suas ações se desenvolveram diante dos contextos da nossa sociedade? Qual o papel de um movimento como esse diante da questão do aborto? Este artigo é resultado da reflexão teórica sobre a prática e a atualidade desse polêmico grupo e suas ações.

Palavras-Chave: Movimentos Sociais - Feminismo - Women on Waves - Gêneros - Patriarcalismo

\begin{abstract}
Women on Waves (WoW) is a social movement created to inform women about the prevention of pregnancy and abortion. Based on the New Social Movements theories and concepts of nationality and patriarchalism, this article seeks to analyze this movement in the contemporary context of feminist movements. How did its actions develop in the contexts of our society? What is the role of such a movement on the issue of abortion? This article is the result of theoretical reflection about the practice and topicality of this controversial group and its actions.
\end{abstract}

Keywords: Social Movements - Feminism - Women on Waves - GenderPatriarchalism

\footnotetext{
"Doutor Ciência Política pela UFSCar. Pesquisador do Grupo de Estudos dos Gêneros do Discurso - GEGE UFSCar e do Laboratório de Estudos em Comunicação, Tecnologia e Educação Cidadã - Lecotec - UNESP.

" Doutoranda em Ciências da Comunicação pela ECA-USP. Pesquisadora do CEDIPP - Centro de Pesquisa em Comunicação Digital e Pesquisa Partilhada da ECA-USP e do Laboratório de Estudos em Comunicação, Tecnologia e Educação Cidadã - Lecotec - UNESP.

${ }^{* * *}$ Especialista em Jornalismo Científico pelo Labjor/UNICAMP e em Linguagem, Cultura e Mídia pela UNESP.
} 


\section{Introdução}

Este artigo visa fazer uma análise do movimento Women on Waves ${ }^{1}$, rede criada por uma médica holandesa com vistas a informar mulheres sobre prevenção de gravidez e aborto. O principal objetivo da organização sem fins lucrativos é evitar a morte de mulheres que se submetem a práticas abortivas clandestinas e perigosas no mundo inteiro. Acreditamos que as atividades dessa rede vão ao encontro das ideias desenvolvidas por Manuel Castells (1999), que entende uma mudança no papel do movimento feminista na sociedade atual por meio do que identifica como o fim da sociedade patriarcalista. Dentre as características que levaram a essa condição podemos apontar a inserção da mulher no mercado de trabalho e o poder da mulher sobre as gestações por meio de pílulas anticoncepcionais e fertilização in vitro, por exemplo. É nesse sentido que inserimos o WoW como um movimento contemporâneo que surge com a intenção de afirmar o poder dessa mulher com relação aos seus desejos e possibilidades para levar adiante uma gestação.

A escolha do movimento foi feita principalmente por suscitar controvérsias e ser absolutamente atual. Ele se insere no conceito de "Novos Movimentos Sociais" (Gohn, 2006), pois atua não apenas localmente, mas também na sociedade globalizada:

Eles usam a mídia e as atividades de protestos para mobilizar a opinião pública a seu favor, como forma de pressão sobre os órgãos e políticas estatais. Por meio de ações diretas, buscam promover mudanças nos valores dominantes e alterar situações de discriminação, principalmente dentro de instituições da própria sociedade civil. (Gohn, 2006, p. 125)

Esses novos movimentos são descentralizados e perderam a noção de liderança e hierarquia, o que Castells (1999) nomeou de "nações na era da informação", tendo as nações perdido a noção territorial e constituindo-se como "comunidades culturais construídas nas mentes e memórias coletiva das pessoas por meio de uma história e de projetos políticos compartilhados" (Castells, 1999, p.69). Ainda segundo Gohn, os novos movimentos são ca-

\footnotetext{
${ }^{1}$ Doravante WoW.

${ }^{2}$ Doravante NMS.
}

racterizados por tratar de aspectos pessoais e íntimos das pessoas. Dessa forma, compreendemos o WoW como um novo movimento social que, apesar de estar ligado à Holanda e atuar sobre suas leis, é global, inclusive por sua atuação em diversos territórios, e por ter como principal meio de divulgação e orientação a web. Iremos agora nos aprofundar mais sobre os NMS para podermos prosseguir na questão do feminismo e na análise do WoW em relação à teoria proposta.

\section{Novos movimentos sociais}

Uma das principais características dos movimentos sociais contemporâneos, emergentes desde a década de 60, é a quebra com a visão estruturalista da cultura, baseada no predeterminismo de valores e conceitos. Além disso, rompe-se com a ideia marxista de ideologia como falseamento da consciência ligada à questão das classes sociais. Ao negar a cartilha marxista, os NMS negam-se olhar o macro como forma de se entender a ação coletiva - partindo então para a necessidade da visão cultural não tão subjugada pelo economicismo (infraestrutura). Dessa confluência surge um novo sujeito que existe em meio a um coletivo difuso e que não se estabelece em uma hierarquia, marcado por atitudes tão contraditórias quanto lutar contra a discriminação do acesso aos bens sociais e ao mesmo tempo ressaltar os efeitos nocivos desta (Gohn, 2006, p. 122). O importante é dizer que tal sujeito já não sofre interpelações da estrutura como a teoria apontava antes e com isso ganha status de ator social.

Por fim, os NMS trazem a política para a esfera da vida, sendo imantado pela realidade cotidiana, e com isso torna-se possível tratar as relações de forma negociada, distanciando do linearismo estrutural que enrijecia os movimentos sociais desde o momento da sua definição até o da ação propriamente dita. De acordo com Maria da Glória Gohn (2006), a ação coletiva só é possível porque os atores conseguem definir-se e interagir em diferentes posições, estabelecendo pluralidade a sua identidade coletiva. Portanto, ao apontar a lupa para os novos movimentos é prioritário entender o processo anterior a eles, ou seja, aquilo que vai dar conteúdo para a identidade do grupo; ver as paixões que movem aquele coletivo. 
Fruto das mudanças da sociedade e da história, os NMS têm a característica peculiar de não se aliarem às estruturas tradicionais dominantes, como agências vinculadas ao Estado ou sindicatos. Como dito anteriormente, seu poder advém da utilização da opinião pública como forma de catalisar e amplificar as bandeiras defendidas. Ao dar espaço para a utilização desse espaço simbólico a autora (Gohn, 2006) aponta que os NMS vão distanciar-se da própria orquestração física que era vigente nos movimentos sociais clássicos: já não se encontram hierarquias definidas, a descentralização ganha espaço, e cria-se um espaço de participação em rede de troca de informação e cooperação.

Por conta da fluidez e do alto grau de simbolismo, a própria formatação teórica dos NMS já não é possível, ressalva a autora (in Gohn, 2006, p.129). Dessa maneira, em sua forma de agir e pensar esses movimentos só podem ser olhados em um porvir, de um lugar onde ainda não foi estabilizado, que ainda se encontra em um processo de constituição. Diz a autora que o que temos são somente diagnósticos de manifestações coletivas. Só que estes não são meras abstrações, mas produzem resultados e geram alterações na sociedade e na esfera política. É de suma importância mostrar que os NMS geram mudanças materiais, reais. Do contrário, cairíamos em um exagerado idealismo.

Posto serem fluídos, os NMS apresentam-se como formas do novo na sociedade pós-moderna e, concomitantemente, penam pela indefinição conceitual. Isso implica em uma miríade de entendimentos e consequências que eles geram. Pelas análises de Gohn (2006), tal incompletude gera críticas que vão desde o entendimento das ações dos NMS - que vão desde a contraposição ao Estado até como prática de reforço deste. Ela assume que esses movimentos não comportam características para serem dispostos como um novo paradigma, mas assume que eles influenciaram na mudança de um certo paradigma vigente. De todo modo, a modalidade de NMS valoriza-se a autonomia dos indivíduos e grupos sociais (processos de singularidades), bem como as práticas cotidianas (cultura) e é a partir disso que pretendemos trabalhar.

Para fins didáticos vamos alinhar o WoW dentro da abordagem neomarxista dos Novos Movimen- tos Sociais. Baseado nos estudos de Claus Offe ${ }^{3}$, a chamada corrente alemã de estudos sobre NMS propõe que o campo de ação não está no espaço da política institucionalizada, oficial, nem da democracia liberal e tampouco do Estado do bem estar social.

Os atores sociais no novo paradigma usualmente são provenientes da classe média e bem informados; atuam em nome da coletividade em função de conteúdos que tratam de direitos humanos, da paz, ecologia, de discriminações, das formas alienadas do trabalho, etc. (Gohn, 2006, p.167).

Na definição, diz Gohn apoiando-se em Offe, é possível encontrar o movimento feminista junto ao movimento estudantil, ecológico, liberação sexual, minorias étnicas e linguísticas etc. O modo de atuação dos NMS é basicamente voltado à informalidade, de forma espontânea, com baixo grau de hierarquia. Como nota para o presente artigo vale ressaltar que tais movimentos agem de maneira não convencional, uma vez que buscam visibilidade e também porque negam a estrutura convencional. Pela definição, os valores defendidos não têm nada de novo. O que destoa são os objetivos políticos declarados - afrontando uma ordem estabelecida. Assim os NMS da corrente neomarxista, diz Gohn (2006), não podem ser considerados pós-modernos porque não criam valores radicalmente novos (ou seja, em nosso caso a discussão prática do aborto já existe nas sociedades), mas que também não são pré-modernos (não é resíduo de algo já discutido).

Uma vez inseridos no contexto dos NMS cabe agora definirmos a questão do feminismo antes de analisarmos o movimento WoW. Até agora somente pincelamos a abordagem sobre a sociedade atual, com suas novas formas identitárias, fundada principalmente na construção coletiva, horizontal e em rede.

\section{O fim do patricarcalismo e a ascensão do feminismo}

Em $O$ poder da identidade, segundo volume da trilogia A era da informação: economia, sociedade e cultura, Manuel Castells (1999) expõe dados e

\footnotetext{
${ }^{3}$ Claus Offe é um professor da segunda geração da Escola de Frankfurt, dis cípulo de Jürgen Habermas e tem trabalhos de sociologia política. Atualmente ministra aulas na Hertie School of Governance, na Alemanha.
} 
análises sobre duas fortes e destoantes características daquilo que ele chancelou como Sociedade em Rede: a globalização e a identidade. As identidades coletivas, segundo o autor, são formas de questionar o Estado-Nação e desafiar a globalização. Desse modo, o feminismo é um dos movimentos que o autor espanhol escolhe como ponto de partida para examinar a identidade coletiva nesse novo contexto social e político que se desenha no mundo dito pós-moderno. Segundo ele, o patriarcalismo é a estrutura tradicional que sustenta todas as sociedades contemporâneas e vem sendo desafiado pelo chamado movimento feminista - um movimento altamente diversificado, mas que encontra homogeneidade no "[...] esforço histórico, individual ou coletivo, formal ou informal, no sentido de redefinir o gênero feminino em oposição direta ao patriarcalismo" (Castells, 1999, p. 211). Portanto o movimento feminista surge como oposição declarada ao patriarcalismo entranhado nas famílias.

Nesse sentido, é possível encontrar manifestações do feminismo em todo o século passado, mas o autor aponta alguns elementos que contribuíram para que somente agora tais ideias tenham ganhado força. Primeiro, temos a transformação da economia e do mercado de trabalho, acompanhada da abertura de oportunidades em relação à educação das mulheres. Depois, seguimos para as mudanças tecnológicas em curso no campo da biologia, farmacologia e medicina, com destaque para a pílula anticoncepcional. Além disso, destaca-se também o desenvolvimento do movimento feminista no contexto social da década de 60 . Por fim, temos a rápida difusão de informação e ideias na cultura globalizada - fruto de um mundo interligado. Estes são alguns sintomas de uma "crise da família patriarcal” que Castells (1999) propõe-se a analisar. Para chegar a tal afirmação ele também se apoia em indicadores que apontam para o crescimento de lares com casais homossexuais, mães ou pais solteiros ou divorciados, entre outros fatores que vão sugerir uma superação próxima do modelo de família nuclear clássica (casais no primeiro casamento e com filhos). Além da mudança na estrutura doméstica, há ainda outros aspectos do movimento feminista que desafiam o patriarcalismo em sua essência, como o lesbianismo e outros movimentos de mulheres.
Podemos fazer uma analogia com o sentido de "casa" feito por Roberto DaMatta (1986, p.17) na sociedade brasileira e, por extensão, na sociedade ocidental. Para o autor a casa é o lugar do conforto, isolado do mundo da rua. É na casa que somos membros de uma família, temos um sinal de pertencimento, do mundo regrado, a hierarquia estabelecida:

Disse que isso se chamava "tradição", e é assim que normalmente falamos desses símbolos coletivos que distinguem uma residência, dando-lhe certo estilo e certa maneira de ser e estar. Mas tais valores podem também ser chamados de "honra" e "vergonha", pois as famílias bem-definidas e com alto sentido de casa e grupo são coletividades que atuam com uma personalidade coletiva bem-definida. (DaMatta, 1986, p.16).

O lugar do contraponto à valoração moral da casa segura é a rua. Essa sim é que comporta a heterogeneidade, o descontrole, ou seja, na rua somos anônimos em meio às massas, perdemos a identidade única para o sentido de povo, da diferença marcante. O paralelo nos serve para dizer que hoje a rua e a casa confundem-se cada vez mais. E qual não é o espanto advindo dessa confusão? Os limites da relação dentro-fora caem por terra, as "famílias bem definidas" perdem a identidade e implica na redefinição de valores. Castells (1999) mostra as lentas acumulações que foram se dando na questão da família desde a década de 70 por meio de estatísticas relacionadas ao divórcio e não casamentos em um amplo número de países. As mudanças podem ser vistas por meio dos dados, por exemplo, entre os quais podemos destacar o ingresso e ascensão da mulher no mercado de trabalho.

\section{Congregação feminina}

Os movimentos femininos, em seu viés contemporâneo, são variados e têm como premissa básica, grosso modo, lutar contra a "dominação masculina”. Castells (1999) assume que atualmente é um movimento discursivo - ou seja, os atos simbólicos são tão importantes quanto as atitudes materiais (como uma manifestação, por exemplo). Há, em suas palavras, uma "polifonia instigante" no movimento feminista. O autor constata assim - e sem atribuir a esse aspecto um caráter negativo ou enfraquecedor do movimento - que o feminismo é a constante bus- 
ca pela identidade feminina, uma vez que esta seria negada pelos homens e família patriarcal.

[...] a essência do feminismo, como praticado e relatado, é a (re)definição da identidade da mulher: ora afirmando haver igualdade entre homens e mulheres, desligando do gênero diferenças biológicas e culturais; ora, contrariamente, afirmando a especificidade essencial da mulher, frequentemente declarando, também, a superioridade das práticas femininas como fontes de realização humana; ou ainda, declarando a necessidade de abandonar o mundo masculino e recriar a vida, assim como a sexualidade, na comunidade feminina. (Castells, 1999, p. 211)

Como a própria definição do conceito de feminismo foi mudando ao longo das últimas décadas, ora pendendo para o liberalismo ora indo para o radicalismo, vamos nos apoiar na tipologia de Spalter-Roth e Schreiber (1995), tal qual Castells apresenta. A primeira tem o movimento feminista como organização nacional, voltado para exigência e obtenção dos direitos iguais; a segunda definição aparece como organizações prestadoras de serviçosformados por redes de grupos locais e com apoio de governos e empresas. Por último é possível encontrar organizações de defesa da mulher, cuja administração é profissional e conta com especialistas, como médicos, advogados, etc, no quadro (Castells, 1999, p.216). Certamente a classificação não abarca toda a gama de movimentos feministas no mundo, mas apresenta um panorama de regularidades que são possíveis de ser encontradas.

Outra questão importante é a evolução desigual dos diversos movimentos feministas, em qualquer abordagem, nos continentes. Enquanto na Europa e América do Norte houve uma infiltração de mulheres nas esferas do poder, o que acabou por gerar uma desfragmentação do movimento, na América do Sul vemos uma lenta aceitação da mulher nas instituições sociais e um patriarcalismo tradicional reinante na Ásia - o que mostra que há ainda muito a se fazer. De todo modo, o autor salienta: "o movimento feminista apresenta formas e orientações muito diferentes, dependendo dos contextos culturais, institucionais e políticos do local em que surgem" (Castells, 1999, p. 224). Este ponto tem validade dentro da análise do WoW, posto que mesmo que o movimento se pretenda global ele se apoiou, em um primeiro momento, na liberalidade política do país de origem.

Por fim, o autor apresenta um quadro analítico dos movimentos feministas. Não cabe neste momento fazer a descrição de cada alínea, que no total são seis (Direitos da mulher; feminismo cultural; feminismo essencialista; feminismo lesbiano; identidades femininas específicas e feminismo pragmático). Iremos somente inserir o WoW dentro das postulações para podemos prosseguir com o estudo. Dentro do que é especificado por Castells (1999) o WoW enquadra-se como "direitos da mulher". De acordo com a tabela, a identidade de tal movimento é voltada para entender as mulheres como seres humanos, tendo como adversário o Estado patriarcal e como meta os direitos iguais (inclusive de ter ou não ter filhos). Veremos então mais sobre o grupo que forma o Women on Waves e sua política (estrutura e dinâmica), para depois adentrar na questão abortiva e suas discussões legais.

\section{Women on Waves}

A organização não-governamental Women on Waves surgiu em 1999 na Holanda por iniciativa da médica Rebecca Gomperts, com a 'missão' de oferecer a possibilidade de aborto para mulheres em início de gestação em locais onde a prática não é permitida pela lei. Em mais de uma década de existência, o WoW também se esforçou em oferecer aconselhamento reprodutivo e instrução sobre métodos de contracepção, como forma de evitar a necessidade da realização do aborto, incentivando o planejamento familiar.

Gomperts, que é médica ginecologista e também formada em artes, teve a ideia de criar o WoW quando ainda era ativista do Greenpeace ${ }^{4}$. Nas viagens feitas a bordo do navio da ONG defensora do meio ambiente, ela sensibilizou-se com as milhares de mulheres que morriam em países subdesenvolvidos em decorrência de métodos abortivos realizados de forma ilegal e sem assistência médica, situação totalmente diversa do seu país de origem, a Holanda.

\footnotetext{
${ }^{4}$ Também uma organização não-governamental com sede em Amsterdã e de atuação mundial. Trabalha em questões relacionadas à preservação do meio ambiente, desenvolvimento sustentável, com campanhas focadas em áreas de florestas, clima, energia nuclear, genética, transgênicos, entre outros temas polêmicos.
} 
Assim, em parceria com o Atleier von Lieshout desenvolveu uma cabine ginecológica móvel facilmente instalada nos navios alugados pela WoW, que são levados às proximidades litorâneas de países onde o aborto ainda não é permitido para o encerramento de gestações indesejadas. A escolha do funcionamento por meio de embarcações deve-se à legislação que vigora além-mar. Tal espaço marítimo é considerado internacional e, portanto, a ele não se aplicam as legislações locais. Dessa forma, é possível realizar os procedimentos abortivos com o acompanhamento de uma equipe médica especializada sem que haja caracterização de crime contra a vida. Vale ressaltar que o aborto no barco é feito ministrando pílulas abortivas - tal procedimento pode ser feito em mulheres com até seis semanas e meia de gravidez sem maiores danos à saúde da gestante.

Contudo, as viagens com os navios são feitas esporadicamente, como forma de chamar a atenção para a causa. Na maioria das vezes, o que a WoW faz é oferecer aconselhamento médico especializado e indicar quais medicamentos podem ser utilizados para a realização relativamente segura do aborto não cirúrgico.

Assim, o principal objetivo da ONG é militar pela legalização da prática do aborto em países onde este ainda não é permitido - o grupo mesmo define-se como "uma resposta à violação dos direitos humanos e médicos das mulheres onde o aborto é considerado ilegal" ao oferecer práticas mais seguras de encerramento de uma gestação indesejada. Com isso, o grupo acredita elevar o poder das mulheres, ao garantir seus direitos de autonomia física e mental. Faz-se imperativo agora ingressarmos na delicada questão do aborto, uma vez que é o cerne do movimento em questão. Prosseguiremos buscando dar um cenário complexo sobre o aborto no mundo e Brasil.

\section{A questão do aborto}

A questão do aborto frequentemente é pauta de discussão não somente na imprensa, mas em diversas estruturas da sociedade, como na família, escola ou igreja. O debate é suscitado de várias maneiras: seja por meio da luta das mulheres em ter ou não os filhos, passando pela interrupção da gravidez em fetos anencéfalos, até a polêmica do uso de células-tronco embrionárias em pesquisas. No Brasil, a prá- tica é crime previsto no Código Penal, sob pena de 1 a 3 anos de prisão para a gestante e de 1 a 4 anos para o médico ou outra pessoa que efetue o procedimento de retirada do feto. Um trabalho publicado em 2008 sistematizou duas décadas de estudos sobre aborto no Brasil e apresentou um dado alarmante: somente no ano de $2005^{5}$ foram 1.054.242 abortos induzidos em território nacional. São cerca de duas mulheres a cada 100, entre 15 e 49 anos que lançam mão do aborto, com predominância para as regiões Nordeste e Sudeste (Diniz e Corrêa, 2008, p.14).

De acordo com o relatório World Population Policies 2009 da Organização das Nações Unidas, desde 1996 cerca de 46 nações dentre 192 que compõem a instituição decidiram liberar as condições da prática abortiva enquanto política pública (18 na África, 10 na América Latina e Caribe, 8 na Ásia, 6 europeus e 4 na Oceania). No mesmo período, 11 países votaram leis mais restritivas (6 na América Latina, 3 na África e 3 na Ásia). As causas para o aumento do número de países são relacionadas à saúde da mulher, seja ela física ou mental, estupro, má-formação do feto, condições socioeconômicas e, por fim, solicitação da gestante (D’Agostino, 2010).

Whereas in an increasing number of developed and developing countries the number of grounds on which abortion is allowed has been rising since the early 1980s, abortion laws and policies continue to be significantly more restrictive in developing countries (ONU, 2010, p.23).

De acordo com a pesquisa da ONU, somente seis nações no mundo não permitem em nenhuma circunstância o aborto. São elas: Chile, República Dominicana, El Salvador, Malta, Nicarágua e Vaticano. Notamos aí o predomínio do que o órgão denomina América Latina e Caribe, com exceção da minúscula República de Malta, um arquipélago localizado no sul da Europa e desenvolvido social e economicamente e o Vaticano, tendo em vista os preceitos cristãos. O Brasil, de acordo com a pesquisa, comporta atualmente dois salvo condutos na questão do aborto: haver risco de morte para a gestante ou o feto ter sido gerado por conta de um estupro - ainda assim, em ambos os casos a prática é rigidamente controlada ${ }^{6}$.

\footnotetext{
${ }^{5}$ Dado mais recente disponível pelo Ministério da Saúde.

${ }^{6}$ As possibilidades de aborto que a ONU considerou: Grounds on which
} 
Assim, dentro dos países democráticos ou com viés de democracia existe quase que um consenso de que o aborto é aceitável para salvar a vida da mulher (96\% de aceitação em países desenvolvidos e $97 \%$ nos países em desenvolvimento). De todas as outras maneiras, existem variações que implicam em maior ou menor rigidez em relação a tal questão da saúde pública. No mundo, em 2003, estima-se que 42 milhões de mulheres abortaram - sendo que metades delas se utilizaram de procedimentos não seguros (ONU, 2010, p.23).

Segundo pesquisa coordenada por Diniz e Corrêa (2008, p.21), existem alguns cenários que levam as mulheres a decidir pela indução abortiva. Apesar de pesquisadores ressaltarem a pouca quantidade de estudos empíricos sobre o aborto (a cada cinco estudos teóricos é feito somente um estudo empírico), utilizar-nos-emos dos dados a fim de estabelecer a trajetória percorrida até se chegar a tal decisão, privilegiando uma abordagem qualitativa. Em geral, a prática tem início com o atraso da menstruação, quando então as mulheres de influência familiar, como mãe, sogras e irmãs, recomendam a tomada de chás a fim de regularizar o fluxo. Se estes não são eficientes, passa-se a um cenário intermediário: ou uma segunda dose do chá medicinal ou o uso de medicamentos, com alta preferência pelo misoprostol ${ }^{7}$. Interessante notar que o uso do medicamento é feito via oral e não vaginal, pois há a crença de que por esse método ainda tenta-se regular a menstruação, enquanto que pela vagina seria assumir o aborto (Diniz e Corrêa, 2008, p.22). Não existe um acompanhamento acadêmico sobre os procedimentos adotados a partir deste momento, que vão variando em uma grande combinação de medicamentos. Finalmente, a pesquisa relata que a maioria das mulheres acaba sofrendo abortos incompletos, que implicam sequelas como dores abdominais até internações. Com o intuito de reduzir a prática, desde 2002 o Ministério da Saúde passou a distribuir a chamada "pílula do dia seguinte". De acordo com Lopes (2009), mesmo não sendo considerada abortiva, a pílula que impede a fixação do óvulo no útero pode ter diminuído em $30 \%$ o número de abortos clandestinos no país. A já

abortion is permitted: (1) to save the woman's life; (2) to preserve physical health; (3) to preserve mental health; (4) rape or incest; (5) foetal impairment; (6) economic or social reasons; (7) on request.

${ }^{7}$ Nome comercial: Cytotec. relatada deficiência nos estudos em relação ao aborto acaba por refletir na ausência de ação contra clínicas clandestinas, muitas delas colocando em prática procedimentos arcaicos e outras ainda que cobram altos valores e voltadas à pessoas com melhores condições econômicas.

\section{Crime Penal}

O aborto é crime contra a vida segundo o Código Penal dentro do território brasileiro ${ }^{8}$, com diversas variações de tipificação. Ao pensarmos tal noção de crime em relação ao movimento que estamos analisando devemos entrar na própria noção de Estado e, consequentemente, na de território. Para tanto, tomaremos mão do conceito secular de Max Weber (2004), em que Estado é uma empresa de caráter político em que a administração tem direito ao monopólio da legítima coerção física a fim de cumprir leis. Advindo da ascensão da burguesia e tendo como relação a distinção entre Estado e sociedade civil (em um plano maior é a divisão entre público e privado), a noção de Estado Moderno compreende então a organização racional de um sistema complexo de interações humanas. Podemos entender pela definição algo como a manutenção da forma política e a burocracia que esta compreende e também de elementos diversos a serem considerados, como, por exemplo, a horizontalização linguística dentro de um espaço físico demarcado e aceito por outros Estados. Dessa maneira, grosso modo, seria dizer que a lei brasileira só vale para dentro do território socialmente acordado como território nação.

E existem duas possibilidades de desafiar tal definição: a primeira, e mais óbvia, é a fronteira marcada convencionalmente outro Estado, onde existem outras formas legais e políticas; e a segunda, são as águas internacionais. Interessante notar que a o subsolo dos países são de controle da União - enquanto as águas e o espaço aéreo têm caráter internacional a partir de medidas determinadas. Águas internacionais são aquelas que se estendem por mais de um país - e só são assim consideradas após 22 milhas náuticas, cerca de 19,31 quilômetros a partir da costa, denominada de mar territorial e até onde se vão

\footnotetext{
${ }^{8}$ Tomaremos o Brasil como exemplo pois é a realidade em que estamos inseridos.
} 
às leis do país em questão ${ }^{9}$. Passada esta metragem passam a valer as regras definidas pela Convenção das Nações Unidas sobre o Direito do Mar junto a cada nação.

\section{Análise e Conclusão}

O WoW tem como missão: "to prevent unwanted pregnancy and unsafe abortions throughout the world ${ }^{10}$ ", sendo que sua base é na Holanda, um país com pouca rigidez em relação ao aborto. Em um primeiro momento, a criadora do movimento propunha utilizar-se de "brecha" legal possível nas águas internacionais. Como a própria Rebecca Gomperts definiu: "This will be a worldwide project (...) We hope to provide a catalyst for legislation and simply want to give women a choice. We want to stress that we are offering a whole range of family planning information to women - not just abortions" (Osborn, 2000). Dessa maneira, Gomperts utilizou-se da experiência adquirida com o Greenpeace para, de certa maneira, burlar o sistema legal dos Estados nacionais a fim da causa do $W o W$. Assim, poderiam atracar como qualquer outro navio em territórios onde o aborto é ilegal e navegar para além da jurisdição local, passando a valer as leis de origem do navio, ou seja, as leis holandesas.

A primeira parada foi feita em 2001, em Dublin, na Irlanda, não sem dificuldades: primeiro o movimento tem que obter periodicamente do governo holandês uma licença para fazer abortos em navios e depois ainda tem que conter a fúria dos protestantes anti-aborto, como ocorreu em vários dos países em que atracaram. "At approximately three o'clock this afternoon, a Dutch ship named Sea of Change will dock in Dublin, to be greeted by a storm of protesters, press and more than a few grateful women" (Giese, 2001). Um terceiro obstáculo é a verba: o jornal inglês The Guardian estipulou que seriam necessárias cerca de 100 mil libras esterlinas ${ }^{11}$ para alugar o navio - que foi chamado de Sea Change (Osborn, 2000) ${ }^{2}$ inicialmente. Além da Irlanda, o projeto previa a ida até Polônia, Malta e países da

\footnotetext{
${ }^{9}$ Lei No 8.617, de 4 janeiro de 1993.

${ }^{10}$ Definição disponível no site da instituição: http://www.womenonwaves. org/article-255-en.html.

${ }^{11}$ O valor é da reportagem publicada em 2000. Em dinheiro de hoje (2011) seria algo como 259 mil reais.
}

América do Sul e África. Nos dois primeiros países, a ida foi levada a cabo ${ }^{12}$, porém demora-se anos para conseguir levar o barco até os países - além da própria Gomperts ter assumido que elas só iriam até nações em que houvesse algum tipo de convite ou pró-atividade para com o Women on Waves, ou seja, não sairiam navegando a esmo. Em Malta, por exemplo, o contato foi com Emmy Bezzina, líder do Alpha Liberal Democratic Party - mas Goumperts só foi até o país em um ato mais político e menos ativista. Ela faria o mesmo em 2004, na Argentina.

Mostrando a evolução do movimento e adequando-se diante das dificuldades, com o tempo arrefeceram as ideias das mulheres navegando pelos mares com o chamado "barco do aborto". Ao mesmo tempo em que era proposto utilizar as águas internacionais, os países visitados passaram a proibir a entrada do próprio barco em seus territórios. O caso aconteceu em Portugal ${ }^{13}$, em 2004. O WoW iria atracar em Figueira da Foz, cerca de 200 quilômetros de Lisboa, mas foi impedido de entrar em águas portuguesas porque o governo invocou o princípio de "passagem não inofensiva por águas territoriais", princípio este estabelecido na Convenção da ONU sobre Direitos do Mar. A alegação foi desrespeito às leis e questões de sanidade pública (Pinto, 2004). Como dissemos, a luta dos movimentos feministas torna-se mais discursiva que efetivamente física sendo que é sempre um jogo de poderes: o WoW se faz valer de um não-território como tática para ajudar mulheres à abortarem e, deste modo, atrair imensa atenção da mídia para as chamadas "campanhas". Por outro lado, a ação gerou reações: os países passaram a tratar Rebecca Goumperts, os colegas e os navios muitas vezes como "inimigos". De um lado a força ideológica pendia para a transposição das fronteiras - visando a liberdade das mulheres em ter ou não o bebê independente do território e independente de jurisdições; de outro passou a existir um recrudescimento da própria noção de Estado, com este defendendo as posições e visões específicas da cultura própria de cada nação.

Quando o governo de Portugal afirma que o barco do WoW não seria inofensivo e que não cumpriria as leis sanitárias do país acaba por assumir a

\footnotetext{
${ }^{12}$ Irlanda em 2001 e Polônia 2 anos depois.

${ }^{13}$ Portugal não permitia o aborto por solicitação da mulher desde 1984.
} 
soberania frente ao movimento utilizando do argumento weberiano da possibilidade de coerção - chegando ao ponto de enviar um barco de guerra para impedir a aproximação territorial. O mesmo aconteceria em 2008 na Espanha: o WoW foi convidado por mais de trinta entidades ligadas à saúde da mulher ou movimentos feministas e atracou em Valência, não sem antes sofrer tentativas de sabotagem. Uma vez mais, como no país vizinho, grupos religiosos e partidos direitistas - além de parte da opinião pública e imprensa - influenciaram e alimentaram a discussão contra as médicas holandesas, transmitindo uma imagem negativa do movimento.

É certo que Gomperts e demais participantes do Women on waves tinham a noção que não iriam navegar em águas tão tranquilas, mas talvez não esperassem dificuldades na própria Holanda, historicamente um país neutro e ideologicamente aberto. Em 2009, o movimento sofreu um baque quando o governo holandês mudou a lei de aborto e serviços de interrupção precoce da gravidez, que passaram a ser considerados crimes. É uma batalha que, além de política, agora terá também que ser travada no âmbito judicial e vai demorar para chegar a uma solução (com isso, as campanhas via barco estão suspensas).

Como vimos, o Women on Waves é baseado na fluidez do movimento de acordo com a necessidade e tão falado "barco do aborto" navega também carregado de simbolismo, tal qual prega a teoria dos Novos Movimentos Sociais. Além disso, não se inserem em nenhuma estrutura tradicional política (órgão de Estado, instituições sociais, empresa), tornando-se algo para além das fronteiras nacionais e, ao mesmo tempo, não renegam a possibilidade de diálogo com os aparelhos vigentes e, portanto, já não pendem para o radicalismo nestas instâncias supracitadas. Também assumimos que os movimentos sociais feministas agora são discursivos, ou seja, buscam o debate e conscientização. Assim, onde o show "valha a pena" o barco vai - trabalhando basicamente com a questão discursiva e atraindo a atenção midiática. A questão do discurso ganha corpo. Uma das responsáveis pelo movimento, Susan Davies (2011), disse:

At the moment there are no ship campaigns happening, nor are there any that we can publically announce at the moment. Ship campaigns are very difficult to organize and depend on the confluence of many factors to be able to happen, and at the moment we are focussed on other projects, but we hope to have the ship sail in the future. ${ }^{14}$

É possível entender a "confluência de fatores" como algo que ultrapassa a questão fronteiriça, atingindo no cerne da ideologia: o WoW só vai até países onde a discussão sobre aborto esteja aquecida e haja possibilidades de um diálogo (no seu sentido amplo) entre a população, autoridades constituídas e o movimento. Dessa maneira, existe uma predisposição social anterior à viagem, seja do barco ou das líderes.

Após a ida do barco, os parlamentos de Portugal e Espanha incrementaram a discussão e acabaram legalizando o aborto. Os portugueses o fizeram em 2007 após referendo, sendo agora possível abortar com até 10 semanas de gravidez a pedido da mulher e independente das razões; já a Espanha era menos rígida, mas em 2010, com a aprovação da chamada "Nova Lei do Aborto", a prática deixou de ser um crime sem pena para se tornar um direito, além de baixar a regra de interrupção da gravidez até a $14^{\text {a }}$ semana de gestação para jovens maiores de 16 anos (sem a necessidade de informar os pais). O crédito de ambas as alterações não podem ser exclusivas do WoW, mas não pode ser negado a contribuição na discussão pública após a visita às nações.

É notável - e aqui o WoW é totalmente inserido no quadro dos Novos Movimentos Sociais - como o movimento é flexível para se adaptar às tendências de sua época, metamorfoseando as práticas de ação, porém sem deixar de lado o conceito do movimento de liberdade e saúde da mulher. No revés da viagem a Portugal, o movimento modificou a prática da ida aos países de barco, passando também a dar auxílio informacional sobre o uso de remédios abortivos. Como é possível encontrar na página do movimento na internet ${ }^{15}$, a primeira década foi marcada por ações bombásticas, despertando o interesse público e dando visibilidade à questão do aborto. Também é límpido para se notar que a resposta foi dada à altura: o Women on Waves foi considerado um perigo em Portugal e o governo holandês impôs restrições legais para a prática do aborto no barco, chegando ao ponto de alterar a lei nacional.

\footnotetext{
${ }^{14}$ Correspondência por e-mail com os autores.

${ }^{15}$ www.womensonwaves.org.
} 
Podemos dizer que, em sua primeira fase, o WoW aprendeu a jogar o "jogo" ideológico - em que as relações pendem de um lado ou outro de acordo com o contexto sócio-histórico, em um movimento dialógico. Após o boom de visibilidade e fama agora chega o momento da segunda fase, como assumem as autores do movimento: com as dificuldades em se colocar o barco no mar, o WoW passou a navegar nas ondas digitais, utilizando as facilidades da era da informação. Parte-se da premissa de que as mulheres são capazes de fazer o aborto somente dominando as informações necessárias - assim, o site do movimento ganhou o status de local do diálogo e conscientização -, tendo como apoio também as linhas telefônicas disponibilizadas nos países para ajudar as mulheres que desejam abortar. Não somente material, a força da conscientização é que está em jogo, chegando a lugares outrora inalcançáveis. Com isso, se ganha um poder adquirido pelas e constituído nas novas formas da sociedade:

A nova forma de poder reside nos códigos da informação e nas imagens de representação em torno das quais as sociedades organizam suas instituições e as pessoas constroem suas vidas e decidem o seu comportamento. Este poder encontra-se na mente das pessoas (Castells, 1999, p.423)

O Women on Waves, de início, era um acinte para duas estruturas solidamente fortificadas e "amigas": o Estado-nação e o patriarcalismo - sendo que ambas coexistem em esferas distintas. Ao subverter a ordem das fronteiras estatais e afrontar a soberania dos países, bem como seus poderes constituídos em face de um bem humanitário, que, no entendimento do WoW, ultrapassa as zonas que confinam os países, o movimento agora assume uma versão ainda mais difusa: não tem um território fixo, navega em ondas de bits, mobilizam símbolos, ao mesmo tempo descentralizado na atuação e centralizado na figura de uma médica, com publicidade online agressiva e imagens fortes, integrado em redes e chegando a países com problemas democráticos (Venezuela e Paquistão) - atingindo o patamar da virtualidade real, que incomodou no passado e o fará no futuro.

\section{REFERÊNCIAS}

CASTELLS, Manuel. 1999. O fim do patriarcalismo: movimentos sociais, família e sexualidade na era da informação In: CASTELLS, Manuel. O poder da identidade, São Paulo, Paz e Terra.

D'AGOSTINO, Rosanne. Lei sobre aborto no Brasil é semelhante à de países da África. In: UOL Eleições 2010, 2010. Acessado em: 23 mai. 2011. Disponível em: http:// eleicoes.uol.com.br/2010/ultimas-noticias/2010/10/14/leisobre-aborto-no-brasil-e-semelhante-a-de-paises-da-africa. jhtm.

DAMATTA, Roberto. 1986. O que faz o brasil, Brasil? Rio de Janeiro, Rocco.

DAVIES, Susan. 2011. Contact - Journalist (mensagem pessoal). Mensagem recebida por romulo_jornalismo@ hotmail.com, 24 mai.

DINIZ, Débora Diniz; CORRÊA, Marilena (cood). 2008. Aborto e Saúde Pública: 20 anos de pesquisas no Brasil, Biblioteca Virtual em Saúde do Ministério da Saúde, Brasília. Acessado em: 23 mai. 201, disponível em: http:// portal.saude.gov.br/portal/arquivos/pdf/aborto_e_saude publica_vs_preliminar.pdf.

DINIZ, Débora Diniz; CORRÊA, Marilena (org). 2008. 20 anos de pesquisas sobre aborto no Brasil - Ministério da Saúde, Secretaria de Ciência, Tecnologia e Insumos Estratégicos, Departamento de Ciência e Tecnologia. Brasília, Ministério da Saúde. Acessado em: 23 mai. 2011, disponível em: http://portal.saude.gov.br/portal/arquivos/ pdf/aborto.pdf.

LOPES, Adriana Dias. 2009. A realidade dos consultórios. Revista Veja, ed. 2097, 28 jan. Acessado em: 23 mai. 2011, disponível em: http://veja.abril.com.br/280109/p_068.shtml.

GIESE, Rachel. Women Seek Sea Change On Abortion. 2001. In: Toronto Star. Opinion, A31, 14 de jun. Acessado em: 9 de jun. 2011, disponível em: http://www.commondreams. org/views01/0614-04.htm; http://pqasb.pqarchiver.com/ thestar/access/425838911.html?FMT $=$ ABS\&FMTS $=$ ABS:F T\&type $=$ current\&date $=J u n+14 \% 2 C+2001 \&$ author $=$ Rachel + Giese $\&$ pub $=$ Toronto + Star\&edition $=\&$ startpage $=$ A.31\&de $\mathrm{sc}=$ Women + seek + sea + change + on + abortion .

GOHN, Maria da Glória (1997) Teorias dos Movimentos Sociais: Paradigmas Clássicos e Contemporâneos, Edições Loyola, 5a edição, 2006, Capítulo 1, pp 23-48. Capítulo 4, pp 121-170.

OSBORN ${ }^{1}$. 2000. World's first floating abortion clinic heads for Ireland. The Guardian. England, 12 jun. Acessado em: 9 de jun. 2011, disponível em: http://www.guardian.co.uk/ uk/2001/jun/12/andrewosborn?INTCMP=SRCH.

${ }^{2}$, Andrew. 2000. Abortion ship to defy protests. The Guardian. England, 16 jun. Acessado em: 9 de jun. 2011, 
disponível em: http:/www.guardian.co.uk/world/2000/ jun/16/andrewosborn?INTCMP=SRCH.

PINTO, Margarida. 2004. Lisboa prohíbe al barco-clínica del aborto entrar en aguas portuguesas. El País. España, 29 ago. Acessado em: 9 jun. 2011, disponível em: http://www.elpais. com/articulo/sociedad/Lisboa/prohibe/barco-clinica/aborto/ entrar/aguas/portuguesas/elpepisoc/20040829elpepisoc_5/ Tes.

SPALTER-ROTH, Roberta; SCHREIBER, Ronnee. 1995. Outsider Issues and Insider Tactics: Strategic Tensions in the Women's Policy Network during the 1980s. In: FERREE, Myra Marx; MARTIN, Patricia Yancy (org). Feminist Organizations: Harvest of the Women's Movement. Philadelphia, Temple University Press, p. 105-27.

United Nations Department of Economic and Social Affairs/ Population Division (UN - ONU). 2010. World Population Policies 2009, United Nations Publication, New York. Acessado em: 23 mai. 2011. Disponível em: http://www. un.org/esa/population/publications/wpp2009/Publication complete.pdf.

WEBER, M. 2004. Economia e sociedade. Brasília, Editora Universidade de Brasília; São Paulo, Imprensa Oficial do Estado de São Paulo.

2001. Metodologia das ciências sociais. 4 ed., Campinas, Editora da Universidade Estadual de Campinas, parte 1.

2001. Metodologia das ciências sociais. 4 ed., Campinas, Editora da Universidade Estadual de Campinas, parte 2 .

Recebido: 04-11-2014

Aceito: 09-02-2015 